\title{
Enhancement in Interfacial Adhesion of Ti/Polyetheretherketone by Electrophoretic Deposition of Graphene Oxide
}

\author{
Lei Pan, ${ }^{1}$ Yunfei Lv (D), ${ }^{1}$ Roy Nipon, ${ }^{2}$ Yifan Wang ${ }^{1 D},{ }^{1}$ Lixiang Duan, ${ }^{1}$ Jingling $\mathrm{Hu},{ }^{1}$ Wenye Ding, ${ }^{1}$ Wenliang Ma, ${ }^{1}$ Jie Tao, ${ }^{1}$ Yu \\ $\mathrm{Shi}^{3}$ \\ 1 \\ College of Material Science and Technology, Nanjing University of Aeronautics and Astronautics, 29 Yudao \\ St., Nanjing 210016, Nanjing, China \\ College of International Education, Nanjing University of Aeronautics and Astronautics, 29 Yudao St., Nanjing 210016, \\ Nanjing, China \\ Department of Mechanical Engineering, University of Chester, Thornton Science Park, Pool Lane,
}

Chester $\mathrm{CH} 2$ 4NU, UK

This article discusses about the significance of graphene oxide (GO) deposition on the surface of a titanium plate by electrophoretic deposition (EPD) method to improve the adhesive strength of $\mathrm{Ti} /$ polyetheretherketone (PEEK) interfacial adhesive. Firstly, the anodic EPD method was applied to a water dispersion solution of $\mathrm{GO}$, and then the morphology and the properties of titanium plate surface were characterized by scanning electron microscopy and contact angle measurements before and after GO deposition. Furthermore, the changes in the properties of $\mathrm{GO}$ after heating at $390 \mathrm{C}$ were characterized by Raman and Fourier transform infrared spectroscopies. According to the results of single lap tensile shear test, the adhesion strength of Ti/PEEK interface after the anodization and deposition of GO was $34.94 \mathrm{MPa}$, an increase of $29.2 \%$ compared with $27.04 \mathrm{MPa}$ of sample with only anodization. Also, the adhesion strengths were 58.1 and $76.5 \%$ higher compared with the samples of only GO deposited (22.1 MPa) and pure titanium (19.8 $\mathrm{MPa}$ ), respectively.

POLYM. COMPOS., 40:E1243-E1251, 2019. (C) 2018 Society of

Plastics Engineers
Correspondence to: L. Pan; e-mail: bettypan @ nuaa.edu.cn Contract grant sponsor: National Natural Science Foundation of China; contract grant number: 51503099. contract grant sponsor: National Key Research and Development Program; contract grant number: 2017NFB0703301. contract grant sponsor: Jiangsu-UK Industrial Challenge Program; contract grant number: BZ2017063. contract grant sponsor: Priority Academic Program Development of Jiangsu Higher Education Institutions. DOI $10.1002 / \mathrm{pc} .24955$

Published online in Wiley Online Library (wileyonlinelibrary.com). (C) 2018 Society of Plastics Engineers

\section{POLYMER COMPOSITES-2019 INTRODUCTION}

There is a strong demand for lightweight, high strength, high elastic modulus, and damage-tolerant structural materials with the development of large aircrafts [1]. The fiber-metal hybrid laminates (FMLs) have a high specific strength and specific rigidity, an outstanding impact resistance, a high damage tolerance, and good resistance performance to fatigue-crack propagation; FMLs have been widely used as the cover and structure materials in many types of airplanes [2, 3]. The fourth-generation hybrid laminates, $\mathrm{Ti} / \mathrm{C}_{\mathrm{f}} /$ polyetheretherketone (PEEK) (TiGr) hybrid laminates, are alternating lay up of titanium sheets and carbon fiber-reinforced PEEK prepreg cured under certain conditions. TiGr has received widespread attention because of the usage of lightweight titanium and high modulus of carbon fiber-reinforced thermoplastic PEEK resin prepregs. Because TiGr has excellent flame retardancy, high damage tolerance and corrosion resistance, good impact resistance, 
easy forming, and recyclability, TiGr has been used in some commercial and military aircrafts $[4,5]$.

There are many interfaces in hybrid laminate composites, and the interfacial bonding strength between metal and resin is a key factor restricting the overall strength of the material [6]. In $\mathrm{Ti} / \mathrm{C}_{\mathrm{f}} / \mathrm{PEEK}$ hybrid laminates, the interface of Ti/PEEK is crucial to the development and applications of TiGr laminates. The adhesive strength of Ti/PEEK interface can be improved by the surface treatment of titanium, constructing special structures or graft substances containing specific functional groups. The common surface treatment methods for titanium alloy can be divided into the following three categories: (1) mechanical methods, such as sandblasting and shot blasting, (2) chemical or electrochemical treatments, such as acid or alkali corrosion and anodic oxidation, and (3) coupling agent graft modification forming a layer of substances containing specific functional groups on the metal surface [7]. Some other methods are also used, such as lithography and microarc oxidation. However, these methods suffer from some new problems such as poor heat and humidity durability, environmental unacceptability, hydrogen embrittlement, and non-high-temperature resistance [8-11].

In this article, a new environment-friendly and interface reinforcement efficient method was used. In the first step of the process, graphene oxide (GO) nanopowder was added to the interface of Ti/PEEK. With a large specific surface area and many oxygen containing groups, such as epoxides and carboxylic acids, GO is a 2D material with a similar carbon structure, excellent mechanical properties and thermal conductivity as graphene. But GO can be easily dispersed in water, making it possible to disperse on a matrix as a single layer to provide the best condition for bonding [12-14]. GO is always used as a nanofiller for different matrixes such as polymers and metals. GO is also used as enhancer in fiberreinforced polymer composites, because the addition of a small amount of GO significantly increases the performance of composite [14-19]. When compared with chemical vapor deposition and other methods, electrophoretic deposition (EPD) is much more economical and easy to implement. Hasan and other researchers [20, 21] used EPD for the deposition of large-area GO films on conductive or nonconductive substrate surface. However, no report shows the influence of GO on the bonding strength of two-dimensional metal plane and resin interface in large area. To solve the interface problems existing in TiGr laminates, in this study, GO was deposited onto a Ti surface by EPD to improve the Ti/PEEK interfacial adhesive strength

Pristine and anodized Ti sheets were used as the metal to observe the changes in surface properties before and after the deposition of GO. Contact angle (CA) was measured using a CA measurement machine. The surface energy, surface morphology, and properties of GO after the deposition were evaluated by scanning electron microscopy (SEM) and Raman spectroscopy. The properties of original GO, water- dispersed GO, and hot-pressed GO were characterized by Fourier transform infrared (FTIR) spectroscopy.

TABLE 1. Physical properties of PEEK

\begin{tabular}{lc}
\hline Physical properties & Value \\
\hline & \\
\hline & 343 \\
Gelt point (C) & 143 \\
Shrinkage rate $(\%)$ & $<2$ \\
Coefficient of linear thermal expansion $\left(\alpha / 10^{-6} / \mathrm{C}^{-1}\right)$ & 47 \\
Dielectric constant & 3.5
\end{tabular}

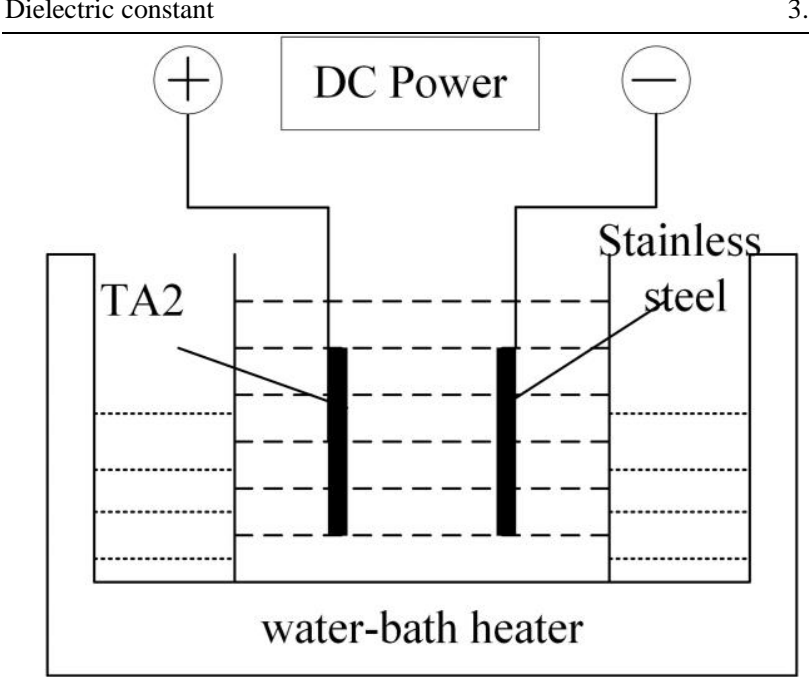

FIG. 1. Schematic of anodic oxidation unit.

Moreover, the effect of deposited GO on the adhesive strength of Ti/PEEK interface was evaluated by comparing the values of single-lap tensile shear strength.

\section{EXPERIMENTAL}

\section{Materials and Sample Preparation}

Commercially pure titanium sheets $(\mathrm{Ti})$ with a thickness of $1.6 \mathrm{~mm}$ were cut into pieces of $100 \times 25 \mathrm{~mm}^{2}$ size. The PEEK film was cut as $12.5 \times 25 \mathrm{~mm}^{2}$ size. Its physical properties are shown in Table 1. Firstly, the GO was synthesized by improved Hummer's method [22, 23]. Then GO was dispersed in deionized water with a concentration of $1.0 \mathrm{mg} / \mathrm{mL}$.

\section{Pretreatment of Ti Surface}

The original Ti surface contains oil and uneven oxidation films due to manufacturing processes and air oxidation. However, the surface oil and original oxidation film should be removed at the beginning. First, a Ti sheet was immersed into acetone and heated at $60 \mathrm{C}$ using a water

TABLE 2. The design and parameters of orthogonal experiment. 
Factors

\begin{tabular}{lccc} 
& \multicolumn{3}{c}{ Factors } \\
\cline { 2 - 4 } Numbers & Voltge $(\mathrm{V})$ & Time $(\mathrm{min})$ & $\begin{array}{c}\text { Goconcentration } \\
(\mathrm{mg} / \mathrm{mL})\end{array}$ \\
\hline 1 & 5 & 1 & 0.5 \\
2 & 5 & 2 & 1.0 \\
3 & 5 & 3 & 1.5 \\
4 & 10 & 1 & 1.0 \\
5 & 10 & 2 & 1.5 \\
6 & 10 & 3 & 0.5 \\
7 & 15 & 1 & 1.5 \\
8 & 15 & 2 & 0.5 \\
9 & 15 & 3 & 1.0 \\
\hline
\end{tabular}

experiment are shown in Table 2. To simplify the experimental procedures and equipment, the electrode distance is based on the same electrode distance as the anodizing device.

TABLE 3. Surface energy parameters of two liquids.

\begin{tabular}{lccc}
\hline $\begin{array}{l}\text { Surface energy }(\mathrm{mN} / \mathrm{m}) \\
\text { Liquid }\end{array}$ & & & \\
& $\gamma$ Lv & $\gamma$ dLv & YpLV \\
\hline Water & 72.8 & 21.8 & 51.0 \\
Ethylene glycol & 48.3 & 29.3 & 19 \\
\hline
\end{tabular}

CA Test
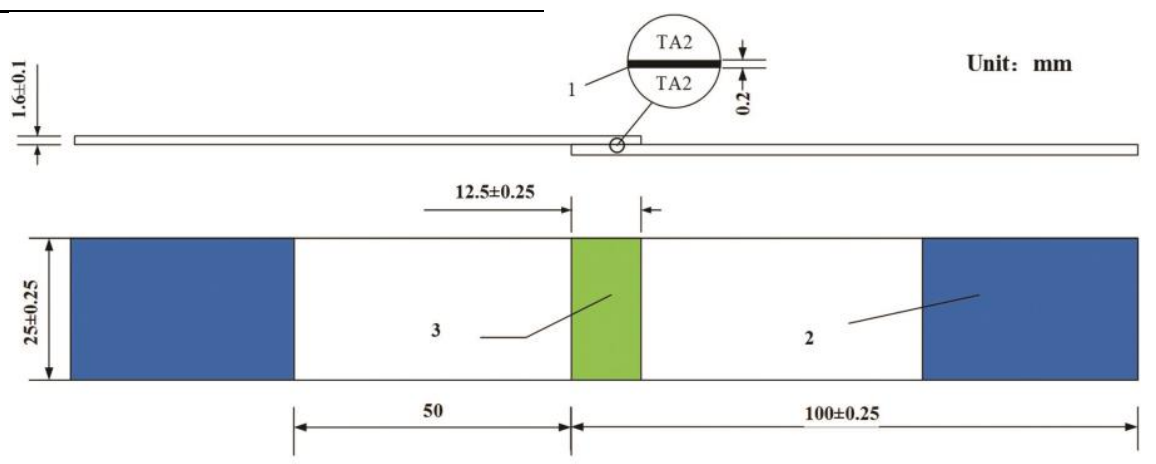

$$
\begin{aligned}
& \text { 1.Adhesive } \\
& \text { 2.Hold zone } \\
& \text { 3.Shear zone }
\end{aligned}
$$

FIG. 2. Sketch of single lap tensile shear specimen.

bath. Then, the Ti sheet was cleaned with deionized water. Finally, the original oxidation film of the Ti surface was removed by treating with a mixture of $85 \%$ nitric acid and $15 \%$ hydrofluoric acid at $40 \mathrm{C}$ for $40 \mathrm{~s}$. The remaining acid was removed by deionized water.

\section{Anodization of Ti Sheet}

$\mathrm{Ti}$ sheets were anodized immediately after removing original oxide film and oil contamination. The electrolyte was an alkaline NaTESi solution ( $\mathrm{NaOH} 300$ g/L, EDTA 30 $\mathrm{g} / \mathrm{L}$, sodium tartrate $65 \mathrm{~g} / \mathrm{L}$, and sodium silicate $6 \mathrm{~g} / \mathrm{L}$ ). Anodization was performed under constant voltage and temperature. The temperature, voltage, and duration were $35 \mathrm{C}, 10 \mathrm{~V}$, and $10 \mathrm{~min}$, respectively. The Ti sheets were used as anode, while stainless steel sheets with same area as $\mathrm{Ti}$ sheets were used as cathode. Installation diagram is shown in Fig. 1.

\section{EPD of GO}

GO powder was scattered in deionized water and dispersed for $30 \mathrm{~min}$ in an ultrasonic environment. Then, the anode deposition method was used, and the experimental device was identical to above mentioned anodizing device. Parameters of EPD were optimized by orthogonal experiment. The parameters and the design of the orthogonal DOI 10.1002/pc
The CA between Ti surface and liquid was measured using the lying-drop method. The droplet size was $6 \mu \mathrm{L}$. In this test, a JC2000D7M CA measuring instrument was used. Water and ethylene glycol were used as the test liquids. The surface energy of titanium plate was calculated using formula (1). The surface energy parameters of water and ethylene glycol are shown in Table 3.

$$
\gamma_{L \nu} 1+\cos \theta=2 \sqrt{\gamma_{\mathrm{SV}}^{d} \gamma_{\mathrm{LV}}^{d}}+2 \sqrt{\gamma_{\mathrm{LV}}^{p} \gamma_{\mathrm{SV}}^{p}}
$$

Where $\theta$ is the measured CA; $\gamma^{d}$ sv and $\gamma^{p}$ sv are the polar parts of the free energy of solid and liquid surfaces, respectively, and the dispersed portions of $\gamma^{\mathrm{d}}{ }_{\mathrm{LV}}$ and $\gamma^{\mathrm{p}} \mathrm{LV}$ are the free energies of solid and liquid surfaces, respectively; $\gamma_{\mathrm{Lv}}$ and $\gamma_{\mathrm{sv}}$ are the free energies of the liquid-gas and solidgas interface of a unit area, respectively. The surface energy of the solid can be expressed as follows:

$$
\gamma_{\mathrm{SV}}=\gamma_{\mathrm{SV}}^{p}+\gamma_{\mathrm{SV}}^{d}
$$




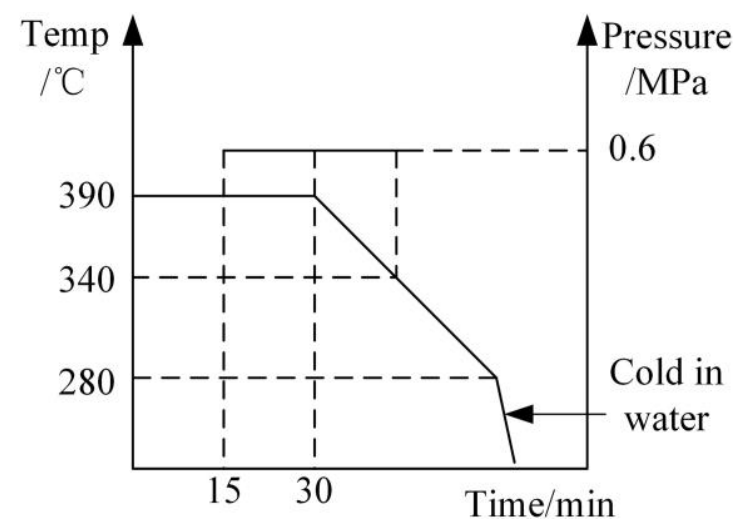

FIG. 3. Sketch of hot pressing process curves of laminate.

\section{Scanning electron microscopy}

The surface morphologies of a titanium sheet after different treatments were observed using a Hitachi S-4800 Type SEM.

\section{Raman and FTIR Spectroscopies}

The Raman spectra of GO before and after the deposition were obtained using a LabRAM HR evolution Raman spectrometer. The IR spectra of the Ti sheets after different treatments were observed using a NEXUS 870 FTIR spectrometer. For each spectrum, 32 scans in the wavenumber range $400-4,000 \mathrm{~cm}^{-1}$ were accumulated at a spectral resolution of $2 \mathrm{~cm}^{-1}$.

\section{Single-Lap Tensile-Shear Experiment}

Strength of Ti/PEEK bonding interface was tested according to the ASTM D1002 standard. The size of the specimen is shown in Fig. 2. A PEEK adhesive film was cut into piece of $25 \times 12.5 \mathrm{~mm}^{2}$ size, and three layers of PEEK adhesive film were placed in the middle of specimen. A steel wire with a diameter of $0.2 \mathrm{~mm}$ was used to control the

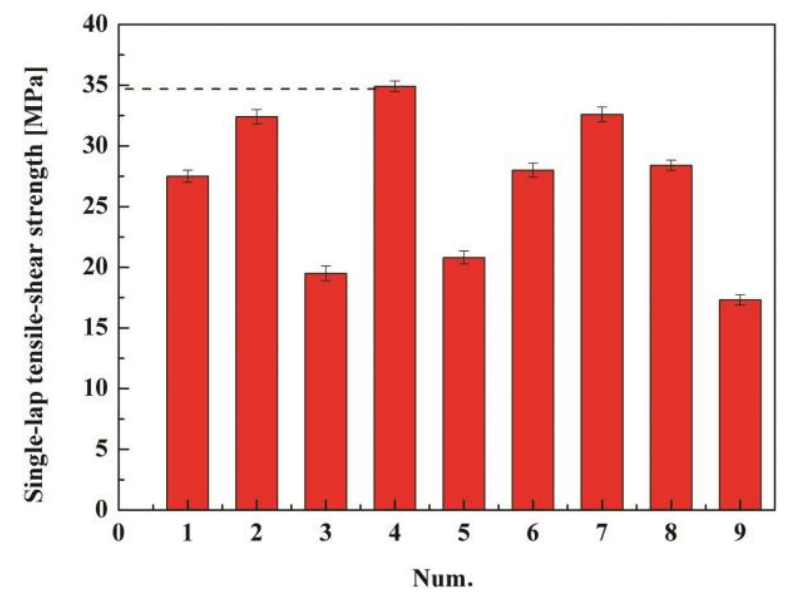

FIG. 4. Single-lap tensile-shear strength of Ti/PEEK under orthogonal experiment.

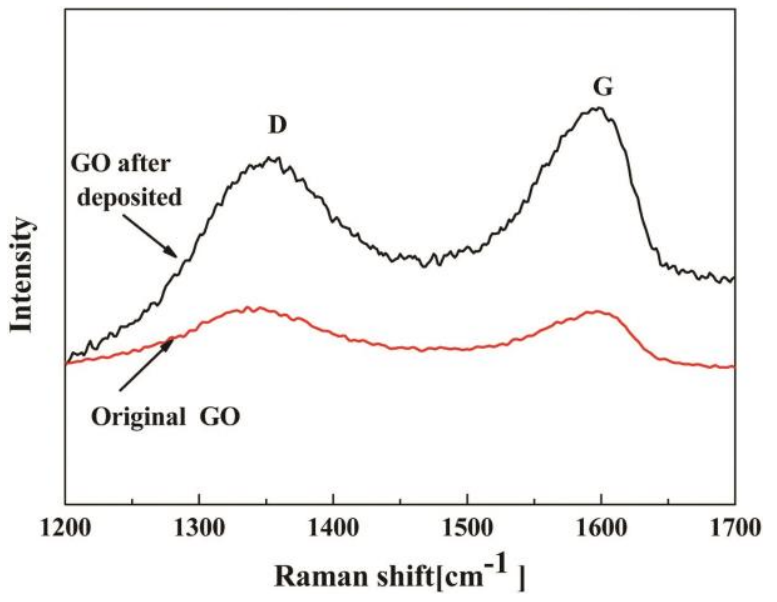

FIG. 5. Raman spectrum of GO.

thickness of the adhesive layers. The tensileshear strength can be calculated according to formula (3).

$$
\sigma=\frac{P}{L \times d}
$$

Where $\sigma$ is tensile shear strength, $P$ is the maximum load value of specimen, $L$ is the length of joint, $d$ is the width of joint.

\section{Hot Pressing of Laminate}

The hot-pressing process is shown in Fig. 3. The specimens were placed in a hot-pressing machine at 390C for $10 \mathrm{~min}$ to completely melt the PEEK films. Then, a pressure of 0.6 MPa was applied. The heating process was completed after maintaining the temperature and pressure for $15 \mathrm{~min}$. The load was released when it cooled down to 340C. The samples were removed for water-cooling after the temperature reached $180 \mathrm{C}$. 


\section{EPD Parameters Optimization}

Tensile shear strength of Ti/PEEK single lap joint of each parameter was studied by orthogonal experiment, and the optimal GO EPD parameter was selected according to the strength value. The strength values of the specimens under different parameters were shown in the Fig. 4.

It can be found that when the deposition ambient temperature, deposition voltage, and deposition duration were: $35 \mathrm{C}, 10 \mathrm{~V}$, and $1 \mathrm{~min}$, respectively, the strength of Ti/PEEK single lap joint was the highest. It indicated that this set of parameters was the optimal parameter.

\section{Raman Spectroscopy}

The Raman spectrum of GO deposited on the titanium after the anodic oxidation is shown in Fig. 5. Two sharp peaks appeared in the Raman spectrum: D peak at 1.295 and $\mathrm{G}$ peak at $1,580 \mathrm{~cm}^{-1}$. D peak originates from the vibration of the carbon atom presented in the $\mathrm{sp}^{3}$ orbital, indicating the structural defects in the carbon plane and the disordered structural of the region; $G$ peak corresponds to the first-order scattering of the $E_{2 g}$ phonon in-plane vibration of the carbon atom presented in the $\mathrm{sp}^{2}$ orbital $[24,25]$. The $\mathrm{I}_{\mathrm{D}} / \mathrm{l}_{\mathrm{G}}$ ratio of original GO is 1.10 , while that of deposited GO is 0.92 . The ratio decreases as the number of defects in the structure increases and the distance between the layers also increases. It indicated that the anodized Ti can react with GO and cause the reduction of GO [18]. There is not only physical adsorption between $\mathrm{Ti}$ and $\mathrm{GO}$,

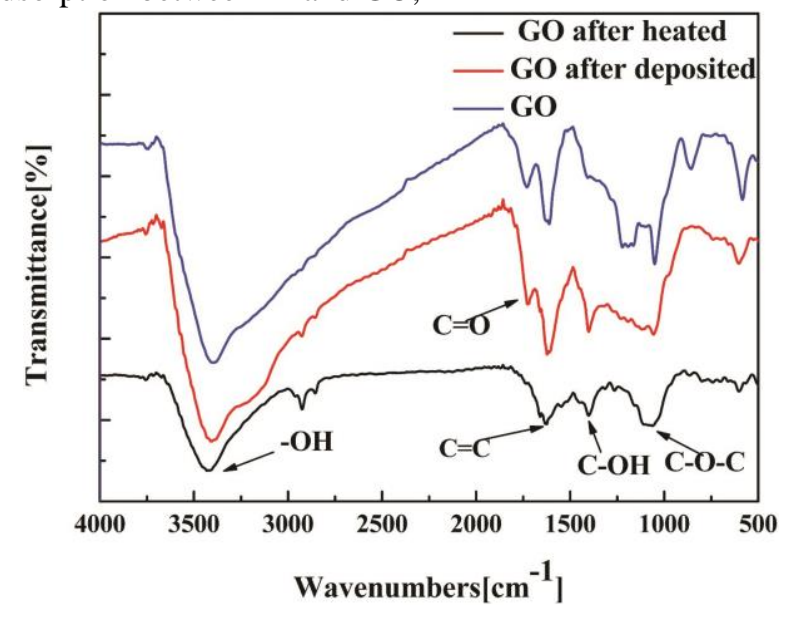

FIG. 6. FTIR spectra of GO after different treatment.

but also chemical bonding. This will definitely play a positive role in improving the interface bonding strength of $\mathrm{Ti} / \mathrm{PEEK}$, which will be discussed in the following.

\section{FTIR Spectroscopy}

Many oxygenated functional groups such as $\mathrm{OH}, \mathrm{C}=\mathrm{O}$, and $\mathrm{COOH}$ exist in the interlayers and edges of $\mathrm{GO}$ with the same carbon structure as graphene. The presence of these groups makes GO to disperse in water easily and improve the wettability of Ti and PEEK adhesive and hence, enhance the interfacial adhesive strength. The changes in the functional groups of GO before and after different treatments were observed by FTIR spectroscopy, because these groups are sensitive to temperature change.

In the FTIR spectrum shown in Fig. 6, the peaks at $3,422,1,734,1,617,1,400$, and $1,209 \mathrm{~cm}^{-1}$ correspond to $\mathrm{OH}$ stretching vibration, $\mathrm{C}=\mathrm{O}$ stretching vibration, $\mathrm{C}=\mathrm{C}$ stretching vibration, $\mathrm{C}-\mathrm{OH}$ deformation vibration, and

TABLE 4. Surface energy of Ti with different treatment.

\begin{tabular}{llll}
\hline Treatment & Water [] & Ethylene glycol [] & Surface energy [mN/m]
\end{tabular}

$\begin{array}{llll}\text { Ti-p } & 65.45 & 31.59 & 41.27 \\ \text { Ti-d } & 32.56 & 24.98 & 68.99 \\ \text { Ti-a } & 44.02 & 28.11 & 56.01 \\ \text { Ti-a-d } & 28.41 & 19.34 & 72.32\end{array}$

$\mathrm{C}-\mathrm{O}-\mathrm{C}$ stretching vibration, respectively [26-28]. The $\mathrm{OH}$ stretching vibration corresponding to $1400 \mathrm{~cm}^{-1}$ peak increased because of an increase in the content of water molecules after the GO was dispersed in water [29]. While heating at $390 \mathrm{C}$ for $1 \mathrm{~h}$, the intensity of $\mathrm{C}=\mathrm{O}$ stretching vibration peak and $\mathrm{C}-\mathrm{OH}$ peak decreased. These indicated that the heat treatment reduced the amount of oxygenated functional groups. The reduction in the corresponding - $\mathrm{OH}$ peak can be attributed to the disappearance of water between layers and the loss of $\mathrm{OH}$ functional groups. After heating, the characteristic peak of $\mathrm{C}-\mathrm{O}-\mathrm{C}$ stretching close to 1,209 $\mathrm{cm}^{-1}$ broadened because of the formation of Ti- O-C bond and its stretching vibration peak overlapped with the $\mathrm{C}-\mathrm{O}-$ $\mathrm{C}$ stretching vibration peak.

\section{CAs and Surface Energy}

The CAs of Ti surface obtained after different treatments with water and ethylene glycol are shown in Fig. 7. Four types of Ti sheets were used: pristine Ti sheet (Ti-p), Ti with GO deposited on the surface (Ti-d), Ti with only anodization (Ti-a), and Ti with anodization and GO deposited on the surface (Ti-a-d). The CAs significantly decreased after the deposition of GO. The CAs of Ti-p with water and ethylene glycol were 65.45 and 31.59 , respectively, and decreased to 32.56 and 24.98 after the deposition of GO, respectively. The CAs of Ti-a with water and ethylene glycol were 44.02 and 28.11 , respectively, while 

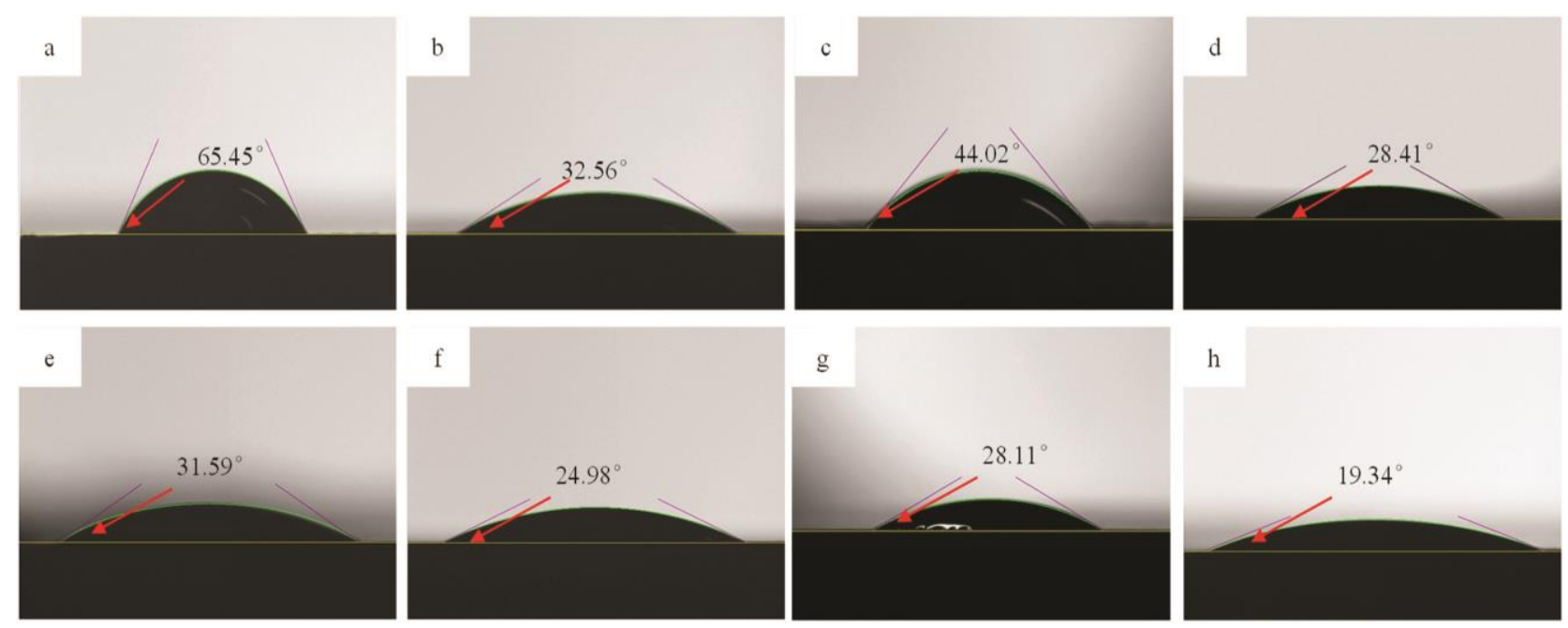

FIG. 7. Contact angle. (a-d) CA with water, (e, f ) CA with ethylene glycol. (a, e) Ti-p, (b, f) Ti-d, (c, g) Tia, and (d, h) Ti-a-d.
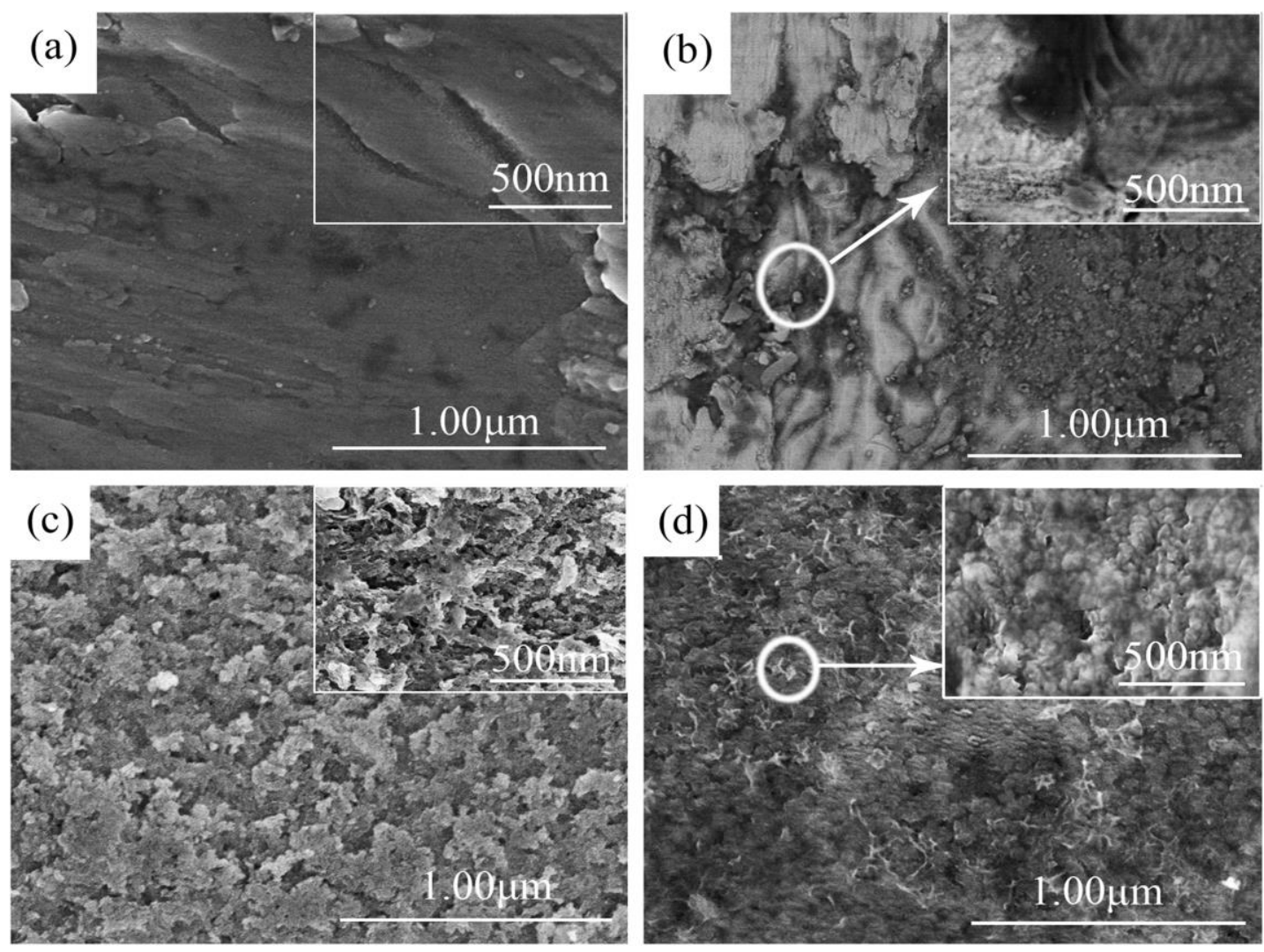

FIG. 8. The SEM images. (a) Ti-p, (b) Ti-d, (c) Ti-a, and (d) Ti-a-d.

after the deposition of GO, they decreased to 28.41 and 19.34 , respectively. The surface energies can be obtained from the CAs. The surface energies are shown in Table 4 . The surface energy of Ti-p was $41.27 \mathrm{mN} / \mathrm{m}$ and increased to 68.99 $\mathrm{mN} / \mathrm{m}$ after the deposition of GO. The anodized Ti surface energy was $56.01 \mathrm{mN} / \mathrm{m}$, but increased to $72.32 \mathrm{mN} / \mathrm{m}$ after the GO deposition. As GO has many oxygenated functional groups, it significantly improved the surface activity of Ti. The increase in surface activity improved the wettability of titanium and PEEK resin, also led to the enhancement in interface bonding strength. 


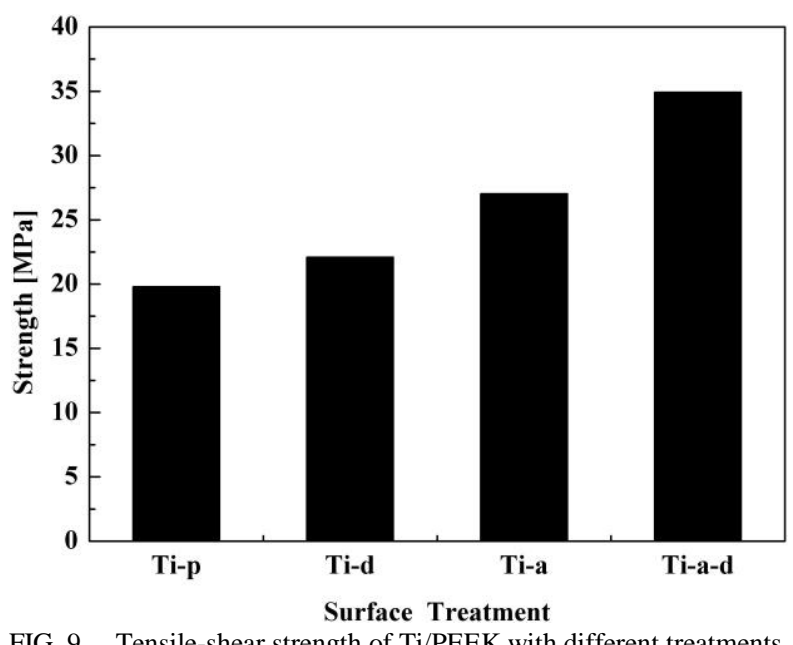

\section{Scanning electron microscopy}

Under the effect of an external electric field, the anode $\mathrm{Ti}$ sheet first loses the outermost electron and then reacts with the ions in the solution, which generating a rough layer of $\mathrm{TiO}_{2}$ film on the surface during the $\mathrm{Ti}$ anodization in an alkaline NaTESi solution. GO is easily dispersed in water and exhibits electronegativity because of the presence of many $\mathrm{COOH}$ and other oxygenated groups. $\mathrm{GO}$ migrates to the $\mathrm{Ti}$ anode and deposits on the surface under the effect of the electric field.

Figure 8 shows the SEM results of Ti surface topogra-

FIG. 9. Tensile-shear strength of Ti/PEEK with different treatments.

phy after different treatments. The surface of pure titanium (Ti-p) showed a slight macroscopic rough topography caused by mechanical machining, but the overall performance is smooth as shown in Fig. 8a. With the deposition of GO on the surface, the contact area of Ti-d with resin increased compared with Ti-p, because there were some folds of GO shown as bright lines in Fig. 8b. A layer of homogeneous nodular oxide film formed on the Ti surface after the anodization in alkaline NaTESi electrolyte, as shown in Fig. $8 \mathrm{c}$. The surface roughness significantly increased, and nanometer particles with diameters of 10-20 nm appeared on the oxide film surface. As shown in Fig. 8d, the GO distribution was not even on the Ti surface after the GO deposition on anodized Ti. Many folds appeared on the GO surface, helping to increase the specific surface area and mechanical interlock between adhesive resin and Ti. Hence, the bonding strength increased

(a)

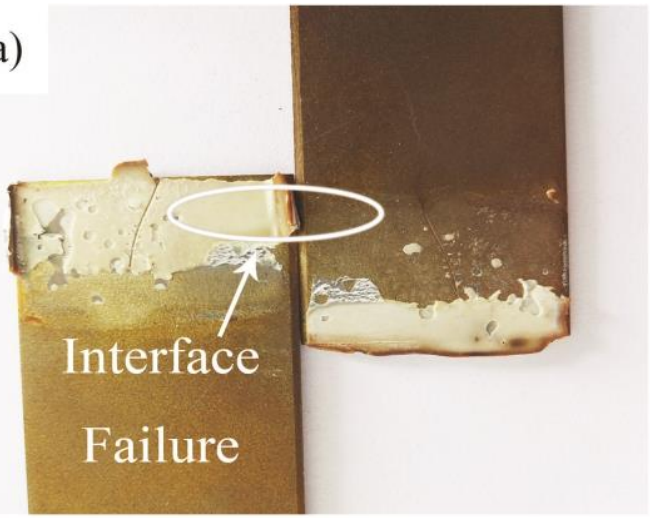

\section{(c)}

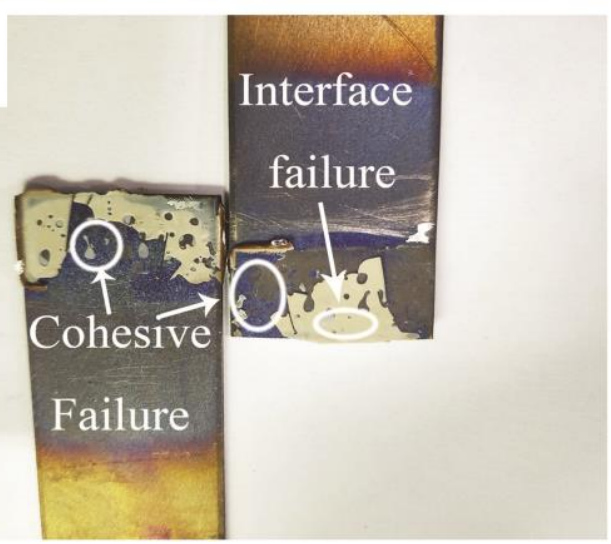

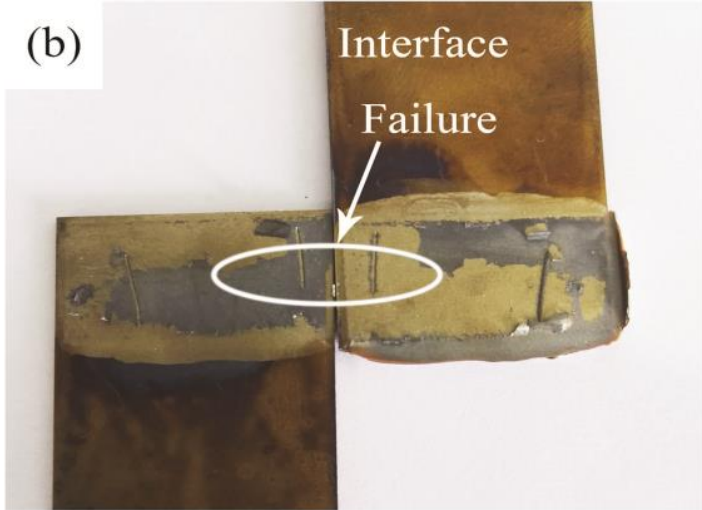

(d)

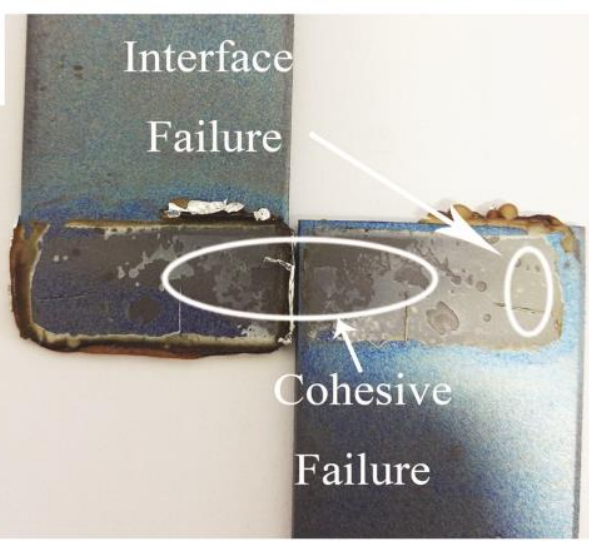


FIG. 10. Images of samples fracture areas after single-lap tensile-shear test.(a) Ti-p, (b) Ti-d, (c) Ti-a, and

(d) Ti-a-d.

significantly even though a slight reunion of GO blocks the anodizing holes, making it un-conducive to glue resin immersion.

\section{Single-Lap Tensile-Shear Strength}

Figure 9 shows the results of single-lap tensile-shear strength. The strength of single-lap tensile-shear of Ti-a-d was $34.94 \mathrm{MPa}$, which is $29.2,58.1$, and $76.5 \%$ higher

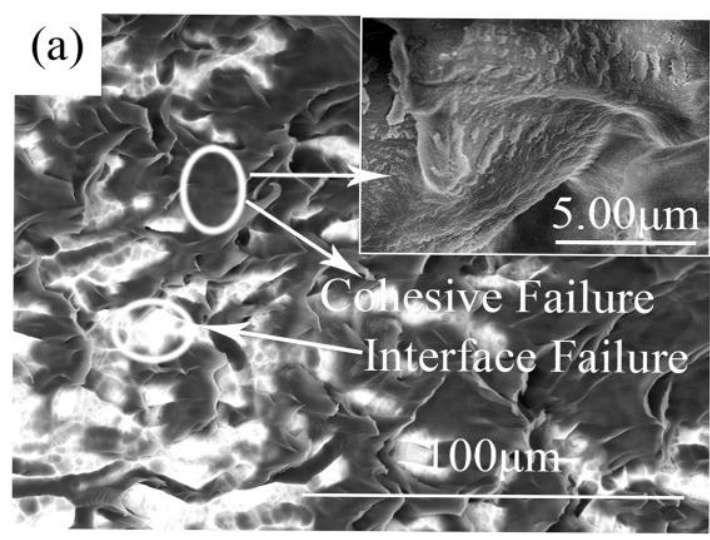
compared with 27.04 MPa of Ti-a strength, 22.1 MPa of the Ti-d strength and 19.8 MPa of the Ti-p strength, respectively. The single-lap tensile-shear strength increased after the deposition of GO, especially with the anodized Ti sheet.

Figure 10 shows the surface morphology of the broken specimen after a single-lap shear test. There are three types of failure models: (1) cohesive failure caused by the breaking of the adhesive, (2) interface failure, only the debonding of metal and adhesive, and (3) a mixture of cohesive and interface failure. The cohesive failure is caused by bond destruction between the resins, whereas the interfacial failure is simply caused by the de-bonding of mechanical

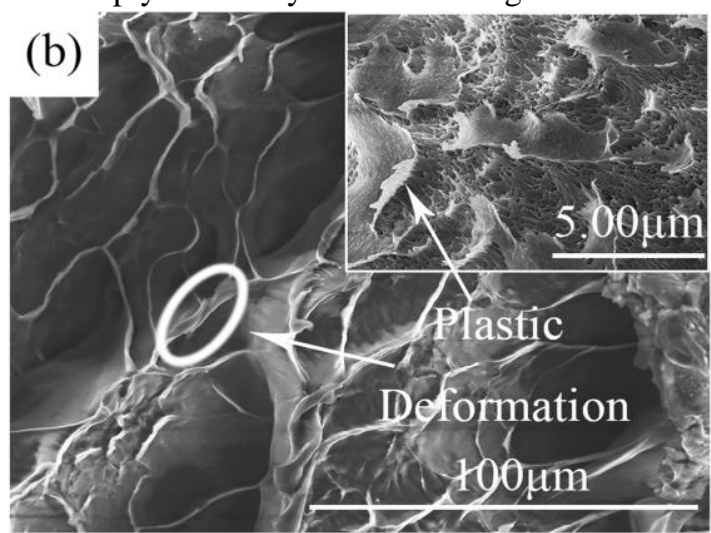

FIG. 11. SEM images of fracture joint. (a) Without GO, (b) With GO deposited.

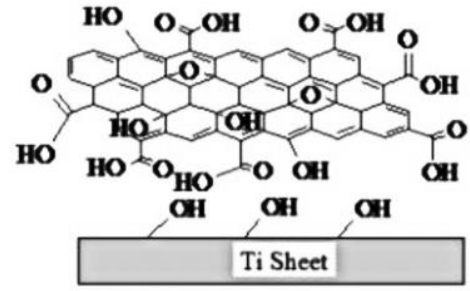

(a)

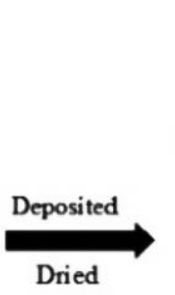

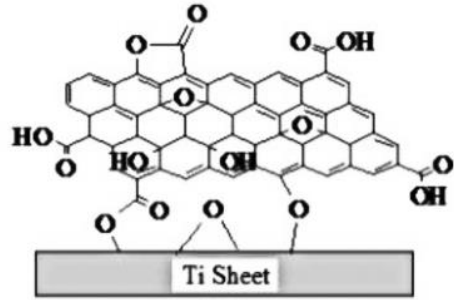

(b)

Hot Press

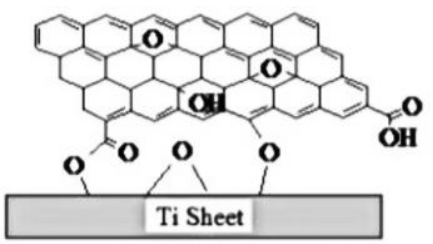

(c)

FIG. 12. Schematic illustration of GO deposited on Ti.

interlock between PEEK and Ti and requires less energy than the former model.

The images in Fig. 10 show that the failures in the joints of Ti-p and Ti-d were mainly caused by interface failure, while the failures in the joints of Ti-a and Ti-a-d were caused by a mixture of cohesive and interface failure. However, it also indicates that the failure of only anodized sample was mainly caused by the third type of failure model. The fraction of interface failure was more than the cohesive failure as shown in Fig. 10c. Furthermore, there was less cohesive failure fraction compared with the GO-deposited sample as shown in Fig. 10d. Figure 10d shows that both sides of the 
sample with GO deposited had many resin residues after the joint fracture, indicating that the failure was mainly caused by cohesive failure. Therefore, the value of single-lap tensile-shear strength of the GO-deposited sample was higher than that of only anodized sample.

Figure 11 shows the micromorphology of the fracture joints. Figure 11a shows that the fracture was caused by a mixture of interface and cohesive failure, and the fracture face of PEEK was plain with a slight plastic deformation. Figure $11 \mathrm{~b}$ shows many holes caused by the tearing of the adhesive during the failure of the joints. Figure 11a and $b$ show that there are more cohesive failure area and more plastic deformation in the fracture joint with GO than that with no GO deposition. This indicates that GO is beneficial in increasing the wettability of resin and $\mathrm{Ti}$, and the strength of the interface bonding is further enhanced due to the increase in contact area of resin and the folds of GO surface, thus increasing the mechanical interlock.

As shown in the FTIR spectrum, Ti-O-C bonds were formed after heating at hot-press temperature, making GO to form strong bonds with the Ti sheet. The principle is shown in Fig. 12a. Because of many folds on the surface of GO, the contact area with PEEK increased by enlarging the specific area. Also, it increased the mechanical interlock with PEEK. Those make it cost more energy to break the joints. On the other hand, the crystalline fraction will increase because the GO can act as the nuclei for the crystal growth of PEEK after hot pressing [30].

\section{CONCLUSIONS}

The SEM, Raman spectroscopy, and CA measurements showed that GO was efficiently deposited on the surface of Ti sheet through EPD. Furthermore, GO made the surface energy of Ti sheet more active. The FTIR spectra showed that after heating at 390C, GO lost some oxygenated functional groups, and new Ti-O-C bonds were formed, which is beneficial to the reinforcement of the joint of $\mathrm{Ti}$ sheet and PEEK.

The adhesive strength of Ti/PEEK was also investigated by the single-lap tensile-shear test to study the effect of GO deposition. The interface adhesive strength of Ti-a-d increased by $29.2 \%$ compared with Ti-a. When compared with Ti-p and Ti-d, it increased by 58.1 and $76.5 \%$, respectively. The large number of folds on the surface of GO not only enlarged the specific area to increase the contact area with PEEK, but also increased the mechanical interlock with PEEK. Hence, a higher performance can be obtained by combining this technique with other mechanical interlocking.

\section{REFERENCES}

1. O.A. Pawar, Y.S. Gaikhe, A. Tewari, R. Sundaram, and S.S. Joshi, Compos. Struct., 123, 350 (2015).

2. B. Kolesnikov, L. Herbeck, and A. Fink, Compos. Struct., 83, 368 (2008).

3. Z. Liu, H. Liu, X. Zhong, T. Hashimoto, G.E. Thompson, and P. Skeldon, Surf. Coat. Technol., 258, 1025 (2014).

4. B.-L. Choi, D.-H. Choi, J. Min, K. Jeon, J. Park, S. Choi, and J.-M. Ko, Int. J. Automot. Technol., 10, 49 (2009).

5. L. Pan, L.X. Duan, Z.M. Zheng, Y.B. Hu, A. Aamir,S. Bhuwan, J. Tao, T.D. Zhao, and Y. Zheng, Mater. Des., 95, 555 (2016).

6. M. Enzo, and C. Antonio, Polymers, 6, 370 (2014).

7. J.H. Xing, Z.B. Xia, J.F. Hu, Y.H. Zhang, and L. Zhong, Corros. Sci., 75, 212 (2013).

8. R. Abedi, and A. Akbarzadeh, Mater. Des., 88, 880 (2015).

9. Y. Liu, X. Zhang, C.C. Song, Y.Y. Zhang, Y.C. Fang, B. Yang, and X.L. Wang, Mater. Des., 88, 810 (2015).

10. A. Kurtovic, E. Brandl, T. Mertens, and H.J. Maier, Int. J. Adhes. Adhes., 45, 112 (2013).

11. S.M. Goushegir, J.F. Dos Santos, and S.T. AmancioFilho,Mater. Des., 83, 431 (2015).

12. P.J. Xu, P.L. Cong, Z. Gao, M. Du, Z.P. Wang, X. Su, and X.Q. Zhao, Polym. Compos., 37, 5 (2016).

13. Y. Li, Y. Zhao, J.M. Sun, Y. Hao, J.D. Zhang, and X. Han,Polym. Compos., 37, 2494 (2016).

14. S.Y. Huang, G.P. Wu, C.M. Chen, Y. Yang, S.C. Zhang, andC.X. Lu, Carbon, 52, 613 (2013).

15. D.R. Paul, and L.M. Robeson, Polymer, 49, 3187 (2008).

16. H. Mahmood, M. Tripathi, N. Pugno, and A. Pegoretti, Compos. Sci. Technol., 126, 149 (2016).

17. P.G. He, B.Y. Huang, L. Liu, Q. Huang, and T.F. Chen, Polym. Compos., 37, 5 (2016).

18. J.J. Jiang, X.M. Yao, C.M. Xu, Y. Su, L.C. Zhou, and C. Deng, Compos. A, 95, 248 (2017).

19. X.M. Yao, X.Y. Gao, J.J. Jiang, C.M. Xu, C. Deng, and J. B. Wang, Compos. B, 132, 170 (2018).

20. R. Ishikawa, P.J. Ko, Y. Kurokawa, M. Konagai, and A. Sandhu, J. Phys. Confer. Ser., 352, 012003 (2012).

21. S.A. Hasan, J.L. Rigueur, R.R. Harl, A.J. Krejci, I.G. Juan, B.R. Rogers, and J.H. Dickerson, ACS Nano, 4, 7367 (2010).

22. S.W. Hummers, Jr, and E.O. Richard, J. Am. Chem. Soc., 80, 1339 (1958).

23. A. Pegoretti, H. Mahmood, D. Pedrazzoli, and K. Kalaitzidou,IOP Conf. Ser. Mater. Sci. Eng., 139, 012004 (2016).

24. S. Hocker, N.H. Smith, H.C. Schniepp, and D.E. Kranbuehl,Polymer, 93, 23 (2016).

25. B. Wicklein, A. Kocjan, G.S. Alvarez, F. Carosio, G. Camino, M. Antonietti, and L. Bergström, Nat. Nanotech, 10, 277 (2015).

26. H.K. Jeong, Y.P. Lee, M.H. Jin, E.S. Kim, J.J. Bae, and Y. 
P. Lee, Chem. Phys. Lett., 470, 255 (2009).

27. K. Duan, X.Z. Hu, and Y.W. Mai, J. Adhes. Sci. Technol., 18, 39 (2004).

28. Y.S. Yu, L.S. Xie, M.H. Chen, N. Wang, and H. Wang, Surf. Coat. Technol., 280, 122 (2015).

29. M.A.S. Sadigh, and G. Marami, Mater. Des., 92, 36 (2016).

30. X.C. Hou, Y. Hu, X.Y. Hu, and D. Jiang, High Perform. Polym., 095400831770154, 30, 406 (2017). 